\title{
A missed C5 vertebral brown tumor causing spinal cord compression and myelopathy: a case report and literature review
}

Babak Mirzashahi ${ }^{1}$, Farzad Vosoughi ${ }^{1}$, Saied Besharaty ${ }^{1}$, and Sadegh Hasani satehi ${ }^{1}$

${ }^{1}$ Tehran University of Medical Sciences

November 30, 2021

\begin{abstract}
We aim to report a patient with vertebral brown tumor in the context of primary hyperparathyroidism presented with shoulder pain. This is the first report of C5 involvement by Brown tumor in a primary hyperparathyroid patient and emphasizes the consideration of cervical vertebral evaluation in patients with persistent shoulder pain.
\end{abstract}

\section{Hosted file}

Brown tumor of the cervical spine7.docx available at https://authorea.com/users/402567/ articles/547432-a-missed-c5-vertebral-brown-tumor-causing-spinal-cord-compression-andmyelopathy-a-case-report-and-literature-review

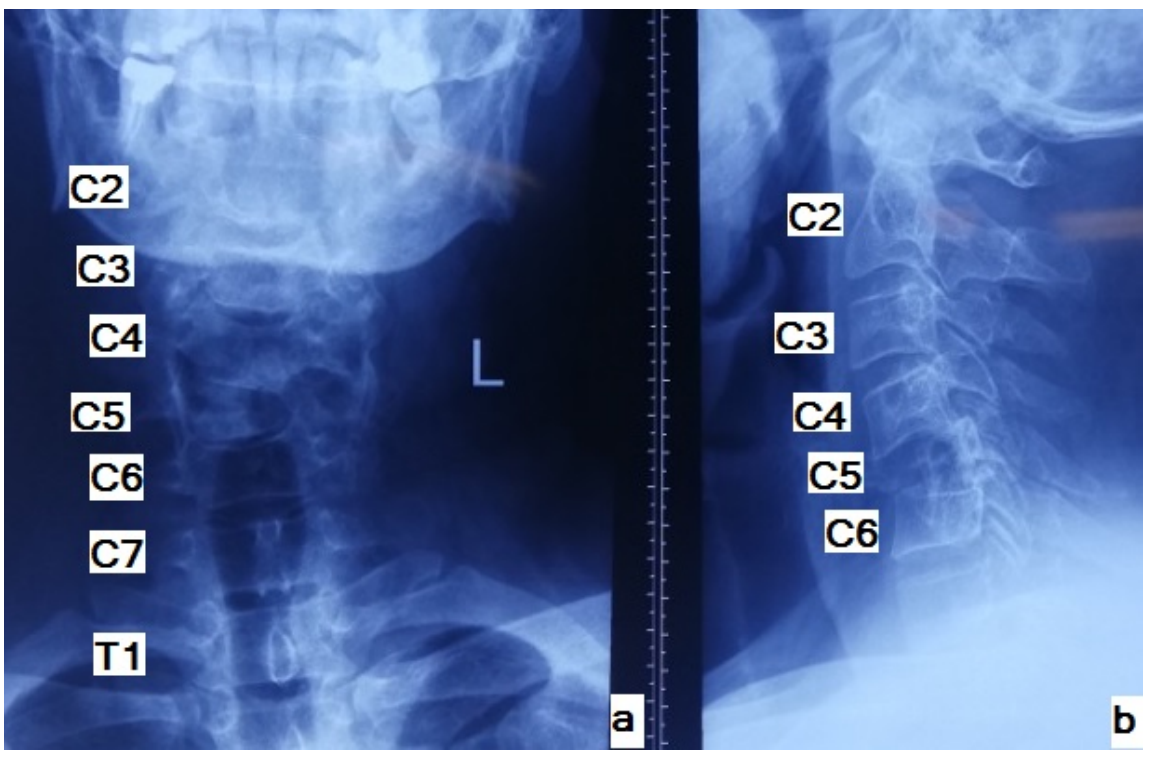



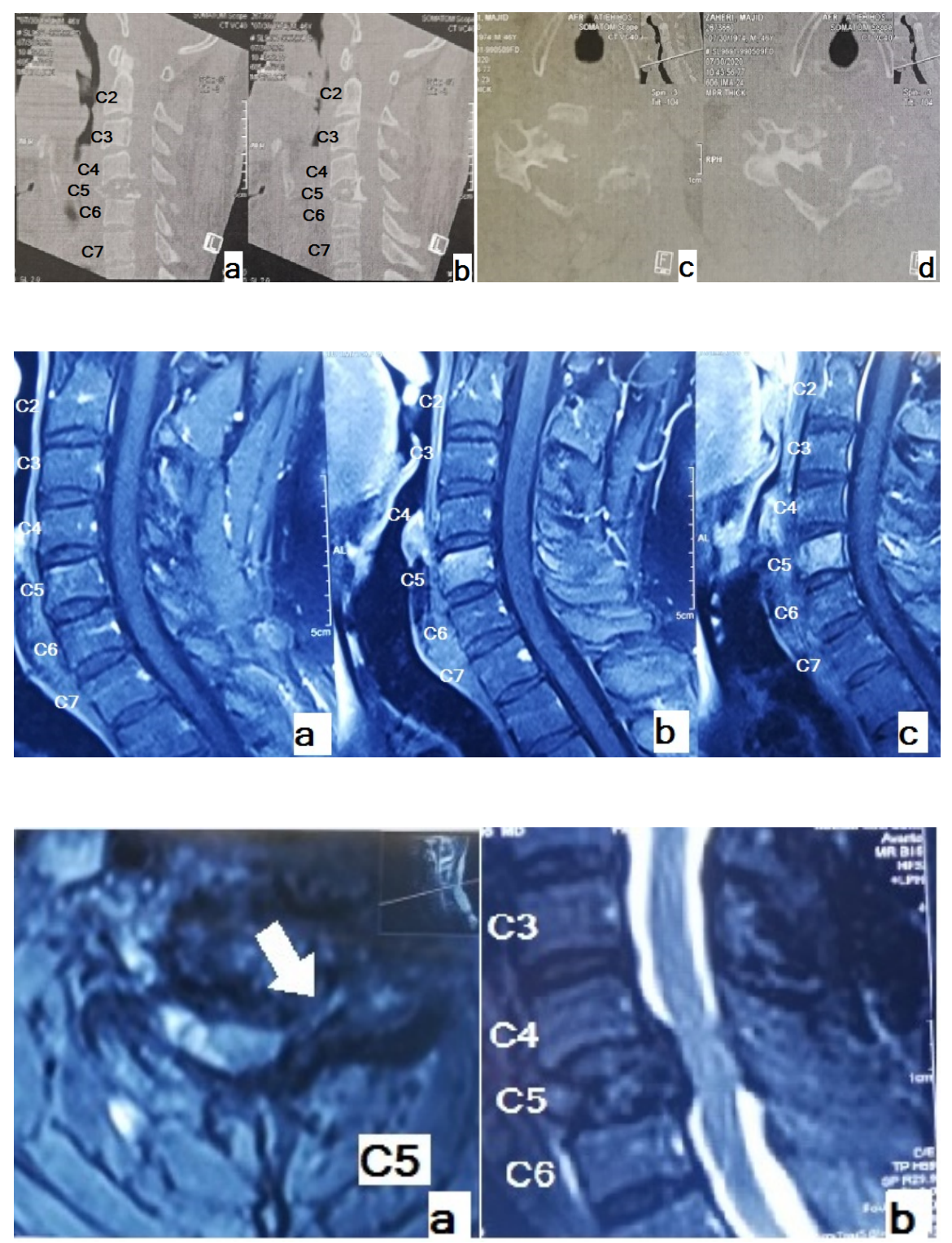

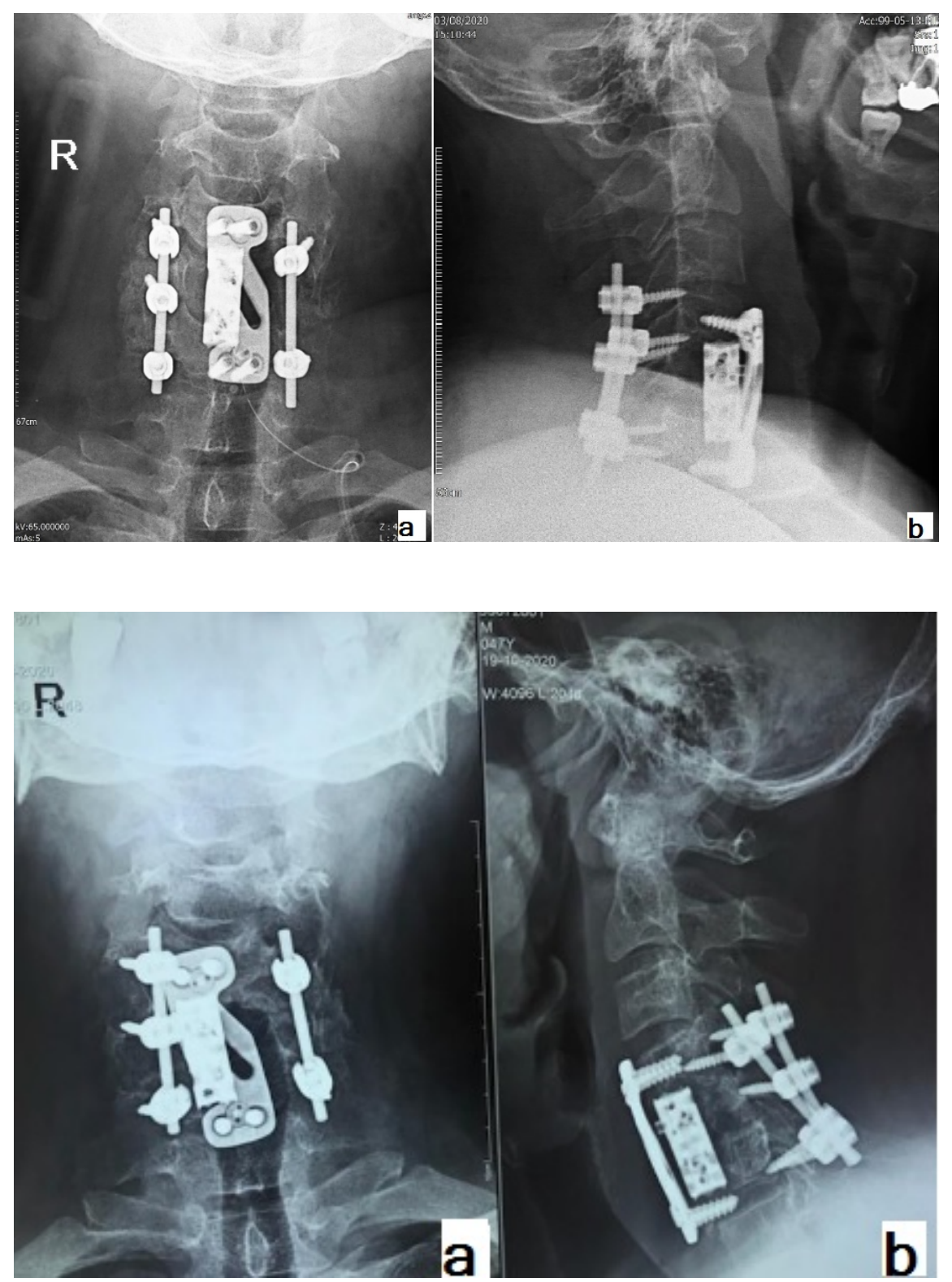